\title{
Aging Well: Promoting Person-Directed Care
}

Angie McAllister and Jeff A Beaty*

Signature Research Institute, LLC, USA, USA

"Corresponding author: Jeff Beaty, Serenity Healthcare, LLC, USA, Tel: 502-568-7800; Fax: 423-370-1200; E-mail: jbeaty@shccs.com

Received date: December 04, 2016; Accepted date: December 20, 2016; Published date: December 22, 2016

Copyright: (C) 2016 McAllister A, et al. This is an open-access article distributed under the terms of the Creative Commons Attribution License, which permits unrestricted use, distribution, and reproduction in any medium, provided the original author and source are credited.

\section{Abstract}

It is evident that outdated clinical models persist in nursing homes today. These outdated models reflect an institutionalized approach to care. Self-doubt, limited resources and lack of knowledge affect the ability of providers to transition to a person-directed model of care. This study demonstrates the effectiveness of a person-directed care model in multiple long term care facilities. Over a period of five years a selection of data from Signature HealthCare communities was taken to demonstrate the efficacy of a person-directed care model in a nursing home setting on specific metrics to include occupancy rates, return to hospital percentages, finance (EBITDA), and Centers for Medicare and Medicaid Services (CMS) 5-star ratings.
\end{abstract}

Keywords: Long term care; Person-directed care; Eden Alternative; Culture change; Quality of life

\section{Introduction}

According to the Department of Health and Human Services (DHHS) (2011), long-term care services include a broad range of health, personal care, and supportive services that meet the needs of older people and other adults whose capacity for self-care is limited because of a chronic illness; injury; physical, cognitive, or mental disability; or other health-related conditions. As of July 2014 there were 15,600 long term care nursing facilities in the United States, providing a total of 1.7 million beds with current occupancy of 1.4 million (CDC/NCHS, 2014) (Figure 1).

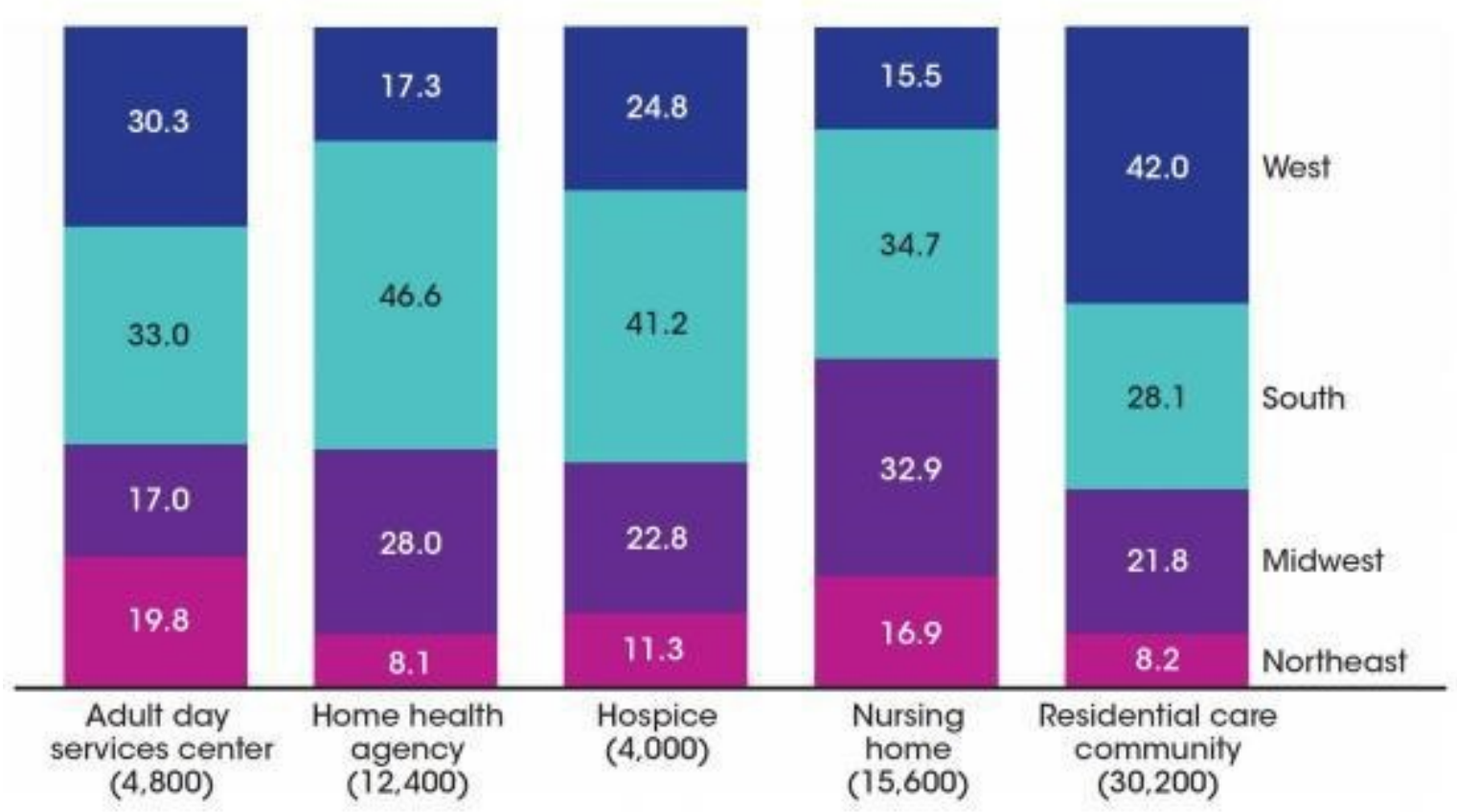

Figure 1: Long-term care services include a broad range of health, personal care, and supportive services that meet the needs of older people and other adults.

By 2050, the number of individuals using long-term care services in any setting (e.g., at home, residential care such as assisted living, or skilled nursing communities) will likely double from the 13 million using services in 2000, to 27 million people. This estimate is influenced by growth in the population of older people in need of care (DHHS, 2005). 
Page 2 of 7

The population 65 and over has increased from 35.5 million in 2002 to 43.1 million in 2012 (a $21 \%$ increase) and is projected to increase to 79.7 million in 2040 . The $85+$ population is projected to increase from 5.9 million in 2012 to 14.1 million in 2040 . Of the older population with long-term care needs in the community, about 30\% (1.5 million persons) have substantial long-term care needs (three or more ADL limitations). Of these, about $25 \%$ are 85 and older and $70 \%$ report they are in fair to poor health (AoA, 2015).

Long term care communities have traditionally been viewed as places dominated by the medical model that values efficiency, consistency and hierarchy of decision-making (Rosher and Robinson, 2005). The hope is that this model will be replaced with a more humanistic model, namely person-directed care model.

Person-directed care is defined as a model of care that is an ongoing, interactive process between elders and caregivers that honor the Elder's dignity and choices in directing his/her daily life. Elders living in traditional long term care settings typically have very little opportunity to coordinate the events of daily life as most of their day is scheduled and have become routine coordinated by systems compliance. It is imperative for long term care providers to realize that in order to achieve elevated quality of life and quality of care outcomes there must be a social quotient that engages the Elder with life around them.

Signature Healthcare recognized this need, specifically within its Hometown segment which serves rural communities. The 60 homes managed by Signature's Hometown segment spans six states. Forty of those homes are listed in the Eden Alternative Registry, a registry managed by the Eden Alternative and utilized to recognize homes actively engaged in culture change.

The Eden Alternative is an organization leading person-directed care initiatives through its principle based philosophy. The Eden Alternative has been focused on changing the culture of care since the early 1990's and not only envelops long term care communities but has also extended other care models across the continuum. The Eden Alternative also believes in order to bring true holistic care providers must first eliminate the three plagues of loneliness, helplessness, and boredom. Signature's Hometown segment began systematically implementing culture change across its homes in 2012 [1].

Given the importance of quality care in skilled nursing communities, it is important to consider methods that may improve staff ability to comply with culture change principles customized to reduce or eliminate loneliness, helplessness and boredom. The persondirected care model is one such innovation. This solution can influence the care provision to elders as well as enhance a community's occupancy rates, return to hospital percentages, finance and CMS 5star ratings.

The major objective of this study was two-fold. The first objective was to assess the effects of person-directed care on quality of life and overall well-being. The second was to assess the efficacy of this solution in providing the ability to improve occupancy rates, return to hospital (RTH) percentages and improving CMS 5-star ratings. The study hypothesis was that communities utilizing the person-directed care model would report a significant improvement in occupancy and finance, RTH percentages, quality of life and well-being as well as improved CMS 5-star ratings.

The research questions are formally stated as:
1. Is there a relationship between person-directed care and culture change on quality of life and well-being in elders located in nursing homes?

2. How are facility occupancy rates and finance affected by the introduction of the person-directed care solution?

3. How is the prevalence of return to hospital (RTH) affected by the introduction of the person-directed care solution?

4. How are CMS 5-star ratings affected by the introduction of person-directed care solution?

5. What are the perceived strengths and weaknesses of the utilization of the person-directed care solution reported by key stakeholders?

\section{Method}

\section{Participants}

Sample: This was a retrospective review study conducted at twentyfour community sites in different geographic areas of the United States. Eight sites were selected from communities that have reached Path to Mastery Milestone 2 with the Eden Alternative. Sixteen homes with similar makeup were selected as control group comparisons. The study was designed to examine the influence of The Eden alternative's ten principles on quality of life and well-being as well as other financial indicators and CMS 5-star ratings.

Sampling: Communities were eligible if they had reached the Eden Alternative's Path to Mastery, Milestone 2. Milestone 2 reflects leadership's commitment to spreading culture change throughout the organization and preparing everyone to take an active role in change initiatives. As leadership's vision moves from dream to reality, employees begin to recognize their role in developing a caring community by identifying strengths and building on what they each bring to the journey.

Study measures: The primary endpoints for this study were metrics discerned from the ten principles and how the facilities met the goals of the principle. The ten principles are delineated as follows:

1. Principle 10. Wise leadership is the lifeblood of any struggle against the three plagues. For it, there can be no substitute.

2. Principle 9. Creating an Elder-centered community is a neverending process. Human growth must never be separated from human life.

3. Principle 8. An Elder-centered community honors its Elders by de-emphasizing top-down, bureaucratic authority, seeking instead to place the maximum possible decision-making authority into the hands of the Elders or into the hands of those closest to them.

4. Principle 7. Medical treatment should be the servant of genuine human caring, never its master.

5. Principle 6. Meaningless activity corrodes the human spirit. The opportunity to do things that we find meaningful is essential to human health.

6. Principle 5. An Elder-centered community imbues daily life with variety and spontaneity by creating an environment in which unexpected and unpredictable interactions and happenings can take place. This is the antidote to boredom. 
Page 3 of 7

7. Principle 4. An Elder-centered community creates opportunity to give as well as receive care. This is the antidote to helplessness.

8. Principle 3. Loving companionship is the antidote to loneliness. Elders deserve easy access to human and animal companionship.

9. Principle 2. An Elder-centered community commits to creating a Human Habitat where life revolves around close and continuing contact with people of all ages and abilities, as well as plants and animals. It is these relationships that provide the young and old alike with a pathway to a life worth living.

10. Principle 1. The three plagues of loneliness, helplessness, and boredom account for the bulk of suffering among our Elders.

Demographic characteristics were selected for each facility [2].

\section{Results}

\section{Principle ten}

Principle Ten teaches us that wise leadership is the lifeblood of any struggle against the three plagues. Initially to transform an organization into something less institutional, wise leadership must prevail and be taught at every level of responsibility within the organization. Signature Hometown initially began this process through many different avenues.

1) Alignment of mission and vision: Senior leaders worked quickly to align all formal and informal leaders with the mission and vision of the organization. This alignment meant that all systems needed to be reconstructed so everyone realized the focus must remain on the vision.

2) Relationships are key to wise leadership: Without the development of relationships on all levels there could never be transformation throughout the organization.

3) Communication of the vision: Communication is essential to growth and development. Proper communication drives out fear of the unknown and this has proven to be the most effective tool during the organization's transformation.

4) Education: Education is the key that unlocks the door of deep systems change. Everyone throughout the organization was educated on the ten principles of the Eden Alternative through various methods. These methods included formal training such as 3 Day Eden Associate training and informal training methods such as blogs, social media and interpersonal communication.

5) Leadership Expectations: Leaders are expected to become educated on the Eden Alternative principles and initiate development of those around them. Key leaders across the organization are also certified nursing assistants which enables them to work closest to the elders on any given day.

6) Leaders as teachers: Signature Hometown also supports the theory that our strongest leaders are our most influential teachers. Across the organization there has been a culture of innovation and continued learning developed to encourage all leaders to excel in their careers.

Through the above methods the organization has seen positive outcomes in key areas. When comparing only the 8 homes who have achieved Path to Mastery, Milestone 2 with the Eden Alternative to homes within our organization who are not on the Eden Registry at this time. Shown on the table below homes who have adopted

Principle 10 not only have higher occupancy but also generated more revenue than those who have not moved from an institutional model of care.

\begin{tabular}{|l|l|l|}
\hline Metric & $\begin{array}{l}\text { Homes Completed } \\
\text { Path To } \\
\text { Mastery Milestone 2 }\end{array}$ & $\begin{array}{l}\text { Homes Not On } \\
\text { Eden } \\
\text { Registry }\end{array}$ \\
\hline Occupancy & $91.40 \%$ & $83.50 \%$ \\
\hline Average \# of Admissions/Month & 20 & 11 \\
\hline Return To Hospital & $14.60 \%$ & $20.30 \%$ \\
\hline EBITDA & $\$ 7.2 \mathrm{M}$ & $(\$ 1.2 \mathrm{M})$ \\
\hline 5-Star Rating & 3.9 Stars & 3.1 Stars \\
\hline
\end{tabular}

Table 1: The table shows homes who have adopted.

Furthermore homes in Tennessee also earned additional revenue through state reimbursement for the widespread adoption of culture change methods. Through QUILTSS reimbursement those homes were able to earn 25 points above the state average for reimbursement (Table $1)$.

Another comparison made within the organization was financial indicators before the adoption of the Eden Alternative against current indicators. Two facilities in Signature Hometown that reached Milestone 2, EBIDTA increased by almost 50\% annualized [3].

\section{Principle nine}

Principle Nine encourages the organization to realize that culture change is a never ending process. This all-encompassing idea encourages long term care providers to seek refuge in the fact that in order to change one must accept the fact that change is constant.

Signature Hometown leaders provided the following conduits to demonstrate the effectiveness of Principle Nine throughout the organization.

1) Initiation of Neighborhood Model: Because the process is never ending, leaders determined that there must be a way to spur growth in all communities that is ongoing. With this being said, the organization began to standardize the neighborhood model concept through the initiation of neighborhood teams in every community.

2) Hardwire the culture change journey: Recognizing that neighborhood development was only one way to achieve success throughout a journey that was ever changing was an important step. Leaders began to build a visual scorecard that would help to hardwire successful elements needed to continue the journey of transformation needed to achieve the vision. Leaders soon developed the Transformation Tree which enabled the homes to earn leaves for milestones achieved.

3) Honoring Elders by sharing stories: Principle Nine also teaches us that human growth should never be separated by human life. This indicates to us that we should always cherish and honor the lives of the Elders we serve. The organization continues to honor the lives of elders through the sharing of their lives through events such as Hall of Fame. The organization also implemented a tool entitled Simply Me that is 
Page 4 of 7

framed in the Elder's room. Simply Me gives brief information about the Elder at the bedside so anyone in the organization can immediately begin to build a relationship with the Elder at any given time. This tool shares information such as the Elder's likes, dislikes, simple pleasures and favorite things.

The Figure below demonstrates that through the development of strong neighborhoods one home was able to positively affect the overall health in key areas (Figure 2). One such area was the reduction of anti-anxiety medications. The home shows a decline in use of these medications over the course of one year from 16\% in November 2013 to $6 \%$ in 2014 . Another key indicator was the decrease in severe pain from $22 \%$ in November 2013 to $9 \%$ in 2014. This home introduced the neighborhood model in October 2013 and began to reap benefits from transitioning to this model in as early as 30 days after implementation.

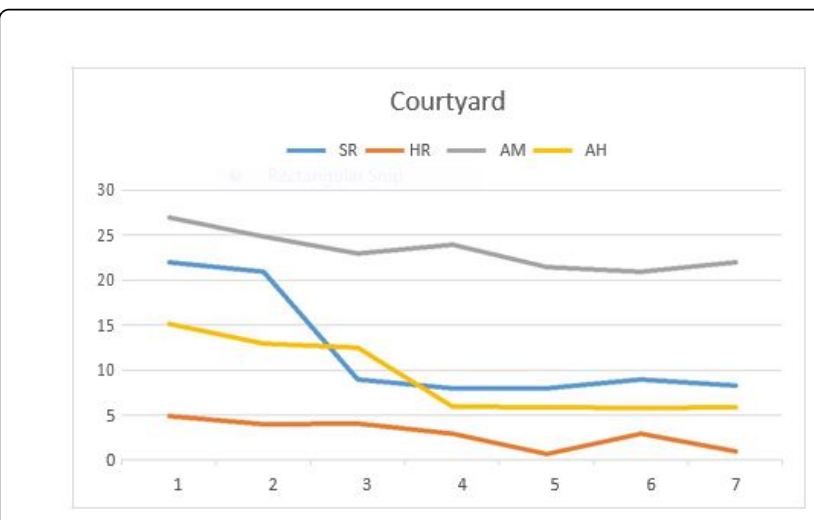

Figure 2: The development of strong neighborhoods one home was able to positively affect the overall health in key areas.

\section{Principle eight}

Principle Eight emphasizes that in order to honor Elders appropriately top down leadership styles must be eliminated. Once eliminated a culture of empowered leadership in which those who are closest to the Elders assist with making key decisions that involve those they care for. This principle is key within the person-directed care movement as it showcases the abilities of those who have the strongest relationships with the Elders. Signature Hometown emphasized these changes through key initiatives that continue to place those who work closest to the Elder in the center of decision making [4].

1) Realign organizational structure: Through the introduction of the Holistic Caregiver Model, homes within the organization are realigning key roles based on the needs of the Elder. This model promotes the effectiveness of cross training to reduce departmental silos. It also centralizes care to the Elder's needs and reduces the amount of people completing tasks related to care.

2) Hardwire programs that move decisions closer to Elders: Through the development of key dining program changes Signature Hometown has been able to move decisions closer to the Elders. These dining changes include a change from the traditional snack cart to a stationary snack area that has snacks available all day for Elders. The stationary cart is also stocked with snacks that the Elders choose as well as seasonal items such as fresh fruit etc.

3) Empower Stakeholders to become "decision makers": Through further development of the Neighborhood Model mentioned in
Principle Nine, Stakeholders are placed in positions to make empowered decisions that affect Elder's lives. Stakeholders also are provided further education through community learning congress events which highlight interactive learning. The development of huddles so that stakeholders can pass on key information to others is instrumental in creating a culture of empowerment.

Data in the table below was collected from four Signature Hometown communities who have completed Mile stone 2 with The Eden Alternative. This data compares nursing turnover prior to implementation of model against current nursing turnover percentages (Table 2).

\begin{tabular}{|l|l|l|l|}
\hline $\begin{array}{l}\text { Home/Year Accepted on } \\
\text { Eden Registry }\end{array}$ & Year & 2011 & 2016 \\
\hline Pickett Care and Rehab & $3 / 15 / 12$ & $30.30 \%$ & $24.20 \%$ \\
\hline $\begin{array}{l}\text { Westmoreland Care and } \\
\text { Rehab }\end{array}$ & $9 / 9 / 12$ & $71.40 \%$ & $53.30 \%$ \\
\hline $\begin{array}{l}\text { Washington Care and } \\
\text { Rehab }\end{array}$ & $9 / 19 / 12$ & $45.40 \%$ & $38.30 \%$ \\
\hline Signature of Erin & $11 / 20 / 13$ & $58.10 \%$ & $40.80 \%$ \\
\hline
\end{tabular}

Table 2: Data compares nursing turnover prior to implementation of model against current nursing turnover percentages.

The table below reflects the implementation of the Holistic Caregiver model at Mountain City Care and Rehabilitation in Mountain City TN. This data demonstrates a few of the positive outcomes post-implementation of the model (Table 3).

\begin{tabular}{|l|l|l|}
\hline Metric & $\begin{array}{l}\text { Pre-Implementation } \\
(3 / 2015)\end{array}$ & $\begin{array}{l}6 \text { Months Post } \\
\text { Implementation } \\
(11 / 20 / 15-12 / 31 / 15)\end{array}$ \\
\hline $\begin{array}{l}\text { Return to Hospital }<30 \\
\text { Days }\end{array}$ & $25 \%$ & $5.00 \%$ \\
\hline Depressive Symptoms & $4.20 \%$ & $2.30 \%$ \\
\hline $\begin{array}{l}\text { Pressure Ulcrers } \\
\text { (New-Worse) }\end{array}$ & $2.00 \%$ & $0 \%$ \\
\hline $\begin{array}{l}\text { Antipsychotic } \\
\text { Medications }\end{array}$ & $25.50 \%$ & $21.50 \%$ \\
\hline $\begin{array}{l}\text { Worker's Comp } \\
\text { Claims }\end{array}$ & 3 & 0 \\
\hline $\begin{array}{l}\text { Increase Assistance } \\
\text { w/ ADLs }\end{array}$ & $25.90 \%$ & $18.30 \%$ \\
\hline
\end{tabular}

Table 3: Data demonstrates a few of the positive outcomes postimplementation of the model.

Through the development of key programs, Signature Hometown has achieved many positive outcomes while implementing Principle Eight. It is believed that through the close development of relationships combined with the empowered stakeholder environment that not only are Elders better cared for clinically but empowered stakeholders produce an innovative culture that leads to problem solving and overall better quality of life for the Elders. 
Page 5 of 7

\section{Principle seven}

Principle Seven teaches that medical treatment should be the servant of genuine human caring and never its master. It is through the enlightenment of this principle that Signature Hometown began to embrace changes within the clinical structure.

Renovating spaces to encourage the rhythm of life to occur. Signature Hometown leaders began to place importance on changing the appearance of the homes. The homes began to deconstruct the traditional nurse's station which is probably the largest icon of the "institutional" model that inhabits today's nursing homes. Instead of nurse's stations homes began to add more living areas so "life" could easily take place from day to day. Other changes included the removal of institutional carts such as linen carts and replacing them with easier access to linens by Elders and their families [5].

Real life initiatives taking the place of medications. The organization also placed deep emphasis on reducing medications that Elders take on a daily basis. This not only improved Quality of Life for the Elder but gave the nurse more freedom and flexibility to spend time building relationships with Elders.Signature Hometown was able to use these methods to promote growth instead of "treatment only" which is a trademark for traditional nursing homes across the country. Through these methods the organization was able to decrease antipsychotic drug percentages by more than $50 \%$ in many homes. The sample of data below is from five homes who joined the Eden Registry in 2012 (Table 4).

\begin{tabular}{|l|l|l|}
\hline Home & $\mathbf{2 0 1 1}$ & $\mathbf{2 0 1 6}$ \\
\hline Westmoreland Care and Rehab & $41.40 \%$ & $3.50 \%$ \\
\hline Riverview Healthcare Center & $52.10 \%$ & $13.60 \%$ \\
\hline Signature Healthcare of Erin & $27.20 \%$ & $0.00 \%$ \\
\hline Washington Care and Rehab & $46.90 \%$ & $8.80 \%$ \\
\hline Chautauqua Care and Rehab & $51.50 \%$ & $10.30 \%$ \\
\hline
\end{tabular}

Table 4: Sample of data is from five homes who joined the Eden Registry in 2012.

One Elder from Washington Care and Rehabilitation was followed over the course of this study. As his medication was decreased, caregivers could easily determine when he was anxious or troubled. He began to sing songs with direct caregivers and no longer became agitated during care. He began to flourish as his medicine was completely eliminated and this greatly impacted his overall quality of life.

\section{Principle six}

Principle Six teaches that meaningless activity corrodes the human spirit while finding things to do that are meaningful is essential to human health. In most nursing homes, the lives of the Elders revolves around the "activity calendar". This principle is critical to the implementation of processes that promote person-directed care.

1) Structured ways to bring meaning to Elder's lives: Built on the belief system that both engagement and entertainment are critical to live meaningful lives, Signature Hometown communities began to weave ways to promote purposeful activity daily. One key factor in moving in this direction was the ability to promote a culture that initiates "simple pleasures" on a regular basis. Through the identification of simple pleasures for both Elders and Stakeholders, homes were able to promote simple moments that increased the ability to promote healthy relationships between the two.

2) Opportunities for Elders to participate in "things they find meaningful": Through the introduction of events that mimic what Elders would pursue on a daily basis outside the realm of long term care, Signature Hometown was able to bring successful living to many. One example of this is introduction of Elder Vacations, an opportunity for those who are physically able to go on overnight trips and out of state vacations. This concept provides opportunities for Elders to experience new things and meet new friends which promoted socialization skills among them.

In the table below, data was collected from 7 Signature Hometown communities who initiated Principle Six into the daily life of the home. The homes are compared against themselves in falls metrics. This data reflects that the opportunity to participate in activities that are meaningful to the Elders actually helped to decrease falls in the entire sample. In some communities falls decreased by $100 \%$ since the implementation of person-directed care practices (Table 5).

\begin{tabular}{|l|l|l|}
\hline Home & 2011 & 2016 \\
\hline Pickett Care and Rehab & $15.40 \%$ & $0.00 \%$ \\
\hline Westmoreland Care and Rehab & $22.90 \%$ & $2.70 \%$ \\
\hline Riverview Healthcare Center & $11 \%$ & $2.10 \%$ \\
\hline Signature Healthcare of Erin & $20.10 \%$ & $5.40 \%$ \\
\hline Mountain City Care and Rehab & $19 \%$ & $7.40 \%$ \\
\hline Washington Care and Rehab & $24 \%$ & $3.40 \%$ \\
\hline Chautauqua Care and Rehab & $21 \%$ & $0.90 \%$ \\
\hline
\end{tabular}

Table 5: Communities falls decreased by $100 \%$ since the implementation of person-directed care practices.

Another positive case study came from an Elder who lived in one of our care communities. Prior to the opportunity to participate in one of the organization's Elder vacations she was overweight and unable to transfer easily. Once she realized there was an opportunity to participate in the vacation event she began to set her own goal to be able to transfer and lose weight so she could attend the vacation. After working hard she reached her goal and was able to attend the vacation. She felt that she could accomplish anything after reaching her goal so she began to work to walk again. This is a positive outcome of how adding meaning and purpose to Elder's lives promotes self-esteem and overall well-being.

\section{Principles five, four and three}

Principles Five, Four and Three are collectively known as the "antidotes". The antidotes teach that through positive actions and greater purpose Elders can achieve a state without loneliness, helplessness, and boredom in their day to day lives. Signature Hometown initiated key areas of focus to integrate these principles into the homes.

1) Create opportunities for Elders to give care: In a world where most Elders have been accustomed to a lifetime of giving care, it is very 
Page 6 of 7

hard for them to become only a recipient of care. Recognizing this need, Signature Hometown began to promote the idea that Elders should lead community service projects as well as other volunteer projects within the organization. To date Elders have led committees that raise funds locally and internationally which serves to fill the Elder's daily life with purpose.

2) Create an environment that places focus on Elder purpose: The organization began to transition the environment to one that began to fulfill the vision to create a place that represented home and life. This step involved the introduction of General Stores in every community. The stores serve as a place in which Elders can work, sell things they create, and come together for socialization. The design mimics a general store of times gone by and promotes positive interactions. Another design change that promotes Elder purpose is the introduction of the Chapel. Signature Hometown recognizes that spirituality is critical to a happy and productive life. The organization added chapels to communities to give those who need it a serene space to practice individualized spirituality.

3) Weave in systems that support the voice of the Elders: Within the walls of a long term community there are many systems which support those who are employed there. However there are few systems that support the voice of the Elder. Through the introduction of strong Elder Councils and committees that support this council, homes have been able to hear and respond to the needs of the Elders. The introduction of the organization's Expressions program also requests for Elders to participate in the giving of ideas in order to create a culture that truly centers on the needs of the Elder.

One such case study came from a lady living in the organization's home in Kentucky. This Elder had socially isolated herself because she felt the home's events were childish and did not meet her needs. Post implementation she can be found acting as the "Store Manager" for the community's General Store. She loves being in the center of the community and is able to now able to engaged in a life that she finds satisfaction in.

\section{Principle two}

Principle Two focuses on the creation of home in an institutional world. The principle teaches the importance of relationships in honoring a life worth living for every Elder. Signature Hometown communities began to take specific actions to truly incorporate principle in the day to day lives of its Elders.

1) Encourage intergenerational relationships: The organization realized the importance of integrating children into the daily lives of Elders and was able to create an environment that supported this daily interaction. Through the implementation of the summer camps, children are afforded the opportunity to spend time with Elders in a supervised setting in both a learning and sharing environment. The integration of summer camps within the communities began to bring spontaneity and variety to the daily life of Elders and many symptoms of depression began to fade away.

2) Encourage animal companionship: In order to truly create home, everyone in the organization agreed that animals were a gateway to companionship that couldn't be filled by a human being. With the addition of dogs, cats, turtles and other animals to communities Elders began to become full of life where it had once faded.

3) Opportunities for growth: Homes within the organization began to adopt opportunities for growth in educational areas. Through monthly educational programs designed to elevate knowledge, Elders have the opportunity for continued growth. Elders also began to serve as teachers within the organization teaching others their skills and eventually becoming "mentors" in different areas.

4) Everyone has the opportunity to be part of the "change": Signature Hometown believes in order to create a culture of innovation and learning, that everyone must be given the opportunity to take part in the change process. Stakeholders can submit their "great ideas" through the Expressions program. Everyone also has the opportunity to participate on committees that facilitate change and implement new ideas within the community. Everyone has an input on the vision and how it should be honored within the home.

5) Physical space changes make it home: Physical transformation has a very real place in propelling the vision forward. Seeing truly is believing and the organization began to work through how to create spaces that truly reflect home. One process change includes the choice of paint colors within the Elder's room. Elders are given opportunity to transform their personal space and choose from a selection of colors. This gives them complete ownership over their personal living areas. Some communities implemented the construction of internet cafes, bistros, and restaurants that serve the Elders select menus. The construction of these areas provides additional dining choices as well promotes an atmosphere that reflects home.

Another important aspect of being "at home" is reinforcing dining systems changes. Through the implementation of a real food first initiative on Signature Hometown community in Tennessee was able to reduce weight loss by over $50 \%$. Elders were given choices between fresh fruit and snacks throughout the day, which enabled the home to decrease the amount of supplements being given in the home. Other key elements to consider was the renovation of their dining room to include the addition of a buffet area and cooking station. This type of arrangement allowed the home to provide cooked to order meals which essentially appealed to the entire population and changed the paradigm in which meal services were delivered. The table below showcases the reduction in weight loss over an 11 month period for this community (Table 6).

\begin{tabular}{|l|l|}
\hline Weight Loss (4/30/15) & Weight Loss (3/31/16) \\
\hline $18.20 \%$ & $3.90 \%$ \\
\hline
\end{tabular}

Table 6: Above table showcases the reduction in weight loss over an 11 month period for this community.

\section{Principle one}

Principle One teaches that loneliness, helplessness and boredom are very real plagues which contribute to the overall decline of Elders living in any environment.

\begin{tabular}{|l|l|l|}
\hline Home & Feb-11 & Mar-16 \\
\hline Pickett Care and Rehab & $12.50 \%$ & $4.00 \%$ \\
\hline Westmoreland & $34.40 \%$ & $3.20 \%$ \\
\hline Mountain City & $31.40 \%$ & $2.20 \%$ \\
\hline
\end{tabular}




\begin{tabular}{|l|l|l|}
\hline Riverview & $6.70 \%$ & $3.00 \%$ \\
\hline
\end{tabular}

Table 7: It showcases the reduction of depressive symptoms in four communities who have fully integrated all principles.

Through the integration of the prior nine principles Signature Hometown began to see the elimination of these plagues in all its forms. The table above showcases the decrease of depressive symptoms by over $50 \%$ in all four homes in which we collected data (Table 7). The organization feels that transforming to a person-directed care model provides many positive outcomes for both Elders living there and stakeholders working there. Overall quality of life has been improved for Elders through the integration of the Eden Alternative principles and philosophy. Improved quality of life leads to an improvement in overall well-being which significantly impacts physical health. While many organizations do not support the transition to a person-directed care model due to perceived increased costs and resistance to change, Signature Hometown has proven this model is effective to pursue.

\section{Discussion}

This study examined quality of life and well-being and other metrics among Elders living in long-term care facilities, compared with a cohort of facilities who had not reached Milestone 2 of The Eden Alternative. This study showed that The Eden Alternative principles has a large impact across domains.

Findings from this study add to the literature regarding The Eden Alternative principles regarding quality of life and well-being in several ways. First, this study examined financial metrics (occupancy rates, return to hospital percentages, EBITDA, and CMS 5-star ratings) of facilities reaching Milestone 2. As a result, findings may reflect different conclusions about Eden principles from those who have not joined The Eden Alternative and implemented these processes. In addition, this research examined the impact of the implementation of the ten principles on quality of life and well-being. Because of this, the study was able to examine particular attributes that changed the quality of life of the elders.

There were several limitations to this study. The particular study only included eight facilities participating in The Eden Alternative, Milestone 2. Findings noted in this study may not generalize to other facilities with The Eden Alternative principles in place or to elders living in other setting and/or long-term care facilities. To possible control for this limitation, one would need to provide a larger sample size to ensure a representative distribution of the population and to be considered representative of groups of people to whom these results will be generalized or transferred.

Despite these limitations, the clear conclusion of this study is that The Eden Alternative principles have a pronounced effect across the domains of clinical, quality of life, finance, and overall well-being among the elders who live in these communities [6].

\section{References}

1. Bergman-Evans B (2004) Beyond the basics: Effects of the eden alternative model on quality of life issues. J Gerontol Nurs 30: 27-34.

2. Brownie S, Neeleman P, Noakes-Meyer C (2011) EXEMPLAR: Establishing the Eden Alternative, T-Min Australia and New Zealand. Contemp Nurse 37: 222-224.

3. Brownie S (2011) A culture change in aged care: The eden alternative(TM). Aust J Adv Nurs 29: 63-68.

4. Coleman MT, Looney S, O'Brien J, Ziegler C, Pastorino CA, et al. (2002) The eden alternative: indings after 1 year of implementation. J Gerontol A Biol Sci Med Sci 57: M422-M427.

5. MacKenzie S (2003) Implementing the eden alternative in australia. J of Social Work in Long-Term Care 2: 325-338.

6. Otsuka S, Hamahata A, Komatsu M, Suishu C, Osuka K (2010) Prospects for introducing the Eden alternative to Japan. J Gerontol Nurs 36: 47-55. 